\title{
$4 \mathrm{~K}-\mathrm{UHD}$ 콘텐츠 제작 워크플로우 중요도 분석
}

장형준, 김광호

서울 과학기술 대학교 IT정책 대학원

\section{Analysis of Factor's Priority for 4K-UHD content workflow}

\author{
Hyung-Jun Chang, Kwang-Ho Kim \\ Graduate School of IT Policy, Seoul National University of Science \& Technology
}

요 약 방송 기술의 최근 흐름은 HDTV와 3DTV에 이어 UHDTV 로 진화되고 있다. UHDTV가 새로운 패러다임으 로 자리매김하고 있으며 우리나라에서도 지상파는 $4 \mathrm{~K}-\mathrm{UHDTV}$ 의 실험 방송과 케이블, 위성에서는 본방송 서비스가 실시되고 있다. 이러한 $4 \mathrm{~K}-\mathrm{UHD}$ 콘텐츠 제작의 활성화를 위한 체계적인 워크플로우가 정립이 필요한 상황이다. 본 연구에서는 전문가 의견을 통한 $4 \mathrm{~K}-\mathrm{UHD}$ 제작 워크플로우의 중요 항목을 도출하고 계층적 분석 방법(AHP, Analytic Hierarchy Process)을 적용하여 4K-UHD 콘텐츠 제작에 있어 중요하게 고려되는 항목을 상호 비교 하였다. 워크플로 우의 상위 계층에는 콘텐츠 제작 기획 측면, 미디어 파일 관리 측면 및 제작 장비의 선택과 운영 측면으로 분류 하 였으며 하위 계층에서는 UHD 제작 STAFF 간의 역할과 트레이닝, 미디어 관리, 저장 장치의 선택과 운영이 상대적 으로 중요하게 평가 되었다. 또한 실시간 $4 \mathrm{~K}-\mathrm{UHD}$ 제작을 위한 워크플로우를 제시하였다.

주제어 : $4 \mathrm{~K}-\mathrm{UHDTV}$, 계층적 분석, 워크플로우, 콘텐츠, 중요도 분석

\begin{abstract}
The recent flow of broadcasting technology, HDTV and 3DTV are being followed to develop UHDTV. UHDTV has established itself as the new paradigm. In Korea, the 4K-UHDTV experimental terrestrial broadcasting and cable and satellite TV services are being carried out in the present. 4K-UHD content creation workflow to enable a systematic formulation is needed. In this study, Through expert opinion 4K-UHD production workflow to derive the important topics and Hierarchical analysis methods (AHP, Analytic Hierarchy Process) is applied to $4 \mathrm{~K}-\mathrm{UHD}$ content creation is important to consider the items were compared to each other. The upper layer has a content creation workflow planning side, the media file management side and operational aspects of the selection and production equipment were classified. In the lower layer, UHD STAFF roles between production and training, media management, selection and operation of the storage device was evaluated in a relatively important. In addition, real-time 4K-UHD suggested workflow for production.
\end{abstract}

Key Words : 4K-UHDTV, AHP, Workflow, Contents, Importance Analysis

\section{1. 서론}

에서 $\mathrm{HDTV}$ 와 3DTV에 이어 $\mathrm{UHDTV}$ 로 방송 기술이 방송 기술의 최근 역사적 흐름에서 보면 디지털 방송 임으로 자리매김하고 있는 것이다. ICT 융합과 미디어 * 본 논문은 2014년 서울과학기술대학교의 학술 연구비에 의하여 지원되었음

Received 20 June 2014, Revised 27 July 2014

Accepted 20 August 2014

Corresponding Author : Kwang-Ho Kim(Seoul National

University of Science \& Technology)

Email:kkh@seoultech.ac.kr

ISSN: 1738-1916
(C) The Society of Digital Policy \& Management. All rights reserved. This is an open-access article distributed under the terms of the Creative Commons Attribution Non-Commercial License (http://creativecommons.org/licenses/by-nc/3.0), which permits unrestricted non-commercial use, distribution, and reproduction in any medium, provided the original work is properly cited. 
생태계의 변화는 방송에서도 매우 다양하고 복잡한 생태 계적 변화를 내포하고 있다. 몇 년 전만 해도 3DTV가 실 감형 방송의 주류를 이루었지만 이제는 초 고화질 방송 (UHDTV) 쪽으로 옮겨 가고 있는 양상이다[1]. 미디어 생태계의 발전 측면에서 단순히 UHDTV 는 기존의 $\mathrm{HDTV}$ 의 4 배 이상의 해상도를 가지는 고해상도 디스플 레이의 양적 팽창 개념에서 실 감형 미디어의 한축으로 초 고화질 TV 와 카메라 기술, 디스플레이 기술, 압축 기 술, 전송 기술, 편집 기술 등 미디어 생태계 전반에 걸친 양적, 질적 발전을 의미하는 매우 중요한 개념이다[2]. 산 업 효과 측면에서도 UHDTV는 방송 기술과 콘텐츠 영역 에 한정되지 않는다. 인프라, 단말, 네트워크 등이 연계되 어 발전되어야 하는 산업적 생산 유발 효과가 큰 분야이 다. UHDTV 디스플레이 보급은 제작 장비 공급으로 이 어지고 이는 콘텐츠 제작에 대한 수효와 제작 과정의 압 축과 전송 기술 개발로 이어진다. 또한 콘텐츠의 유통 등 UHDTV 방송의 가치 사슬이 연계되어 있다[3]. 영화와 $\mathrm{TV}$ 의 경계가 무너지고 있는 현 상황에서 UHDTV 가 의미하는 것은 또 다른 산업적 발전과 미디어 생태계의 또 다른 진화를 예고하는 것이라 할 수 있다. 2012 2014 $\mathrm{NAB}$ 에서도 UHDTV 가 차세대 방송의 주류로 자리매 김 하였으며 영화나 드라마 쪽에서는 $4 \mathrm{~K}$ 제작이 보편화 되고 있는 실정이나 우리나라 방송에서의 UHDTV는 아 직 실험 방송 수준에 그치고 있는 실정이다. 현재는 $4 \mathrm{~K}$ 로 인식되고 있는 UHDTV 의 제작과 전송에 대한 표준 화 규격과 워크플로우가 정립되지 못한 상황이며 정책적 인 정립도 요구되고 있다[4]. 또한 충분한 제작과 전송, 송출 규격의 워크플로우를 검토하여 효율적인 표준화를 정립할 필요가 있다. 특히 UHDTV 의 제작 과정에서 보 면 아직은 파일 기반의 초기 단계로 실시간 촬영 시간보 다 많은 렌더링 시간과 편집 본의 실시간 모니터링이 어 려운 여건을 감안하면 여전히 $4 \mathrm{~K}-\mathrm{UHDTV}$ 의 제작은 어 려운 실정이다[5]. 또한 대부분의 $4 \mathrm{~K}$ 카메라가 Raw File 형태로 데이터가 생성되는 관계로 시간과 비용의 측면에 서 대량의 콘텐츠 생산이 어려운 점이 있다. 기존 $\mathrm{UHDTV}$ 의 연구에서는 주로 증가된 모니터의 해상도에 관한 연구와 산업적 동향에 대한 일반적인 연구, 그리고 정책적 발전과 방향성 등에 대한 연구가 한계점이었다.
본 연구에서는 UHDTV의 발전 방향에 대해서 현실적 이고 구체적인 제작 과정의 특징과 차이점을 살펴보고자 한다. 2장에서는 기존의 $4 \mathrm{~K}-\mathrm{UHDTV}$ 의 기술적 특징과 제작 특성의 변화 그리고 서비스 동향 등을 살펴보고 3장 에서는 연구 문제 및 연구 방법을 통해 UHDTV 콘텐츠 제작 워크플로우의 중요 항목을 도출하고 도출된 항목들 의 상관관계를 통해 $4 \mathrm{~K}-\mathrm{UHDTV}$ 콘텐츠 제작 워크플로 우의 중요도 문제를 제시한다. 4 장에서는 $4 \mathrm{~K}-\mathrm{UHDTV}$ 콘텐츠 제작에 관한 구체적인 워크플로우 항목을 제작 현장에 있는 전문가들의 인터뷰를 통해 도출하고 도출된 항목을 계층별 요인으로 나누어 $\mathrm{AHP}$ 분석을 통해 중요 도를 비교한다. 결론 부분에서는 $4 \mathrm{~K}-\mathrm{UHDTV}$ 콘텐츠 제 작을 위한 워크플로우의 주요 특징에 대한 상호 중요도 분석을 통해 실시간 제작 워크플로우를 제안하고자 한다.

\section{2. 이론적 배경}

\section{1 영상 포맷 및 규격}

$\mathrm{UHD}$ 방송은 $\mathrm{HDTV}(2 \mathrm{~K}: 1,920 \mathrm{x} 1,080)$ 가 제공하는 화질 보다 4 배에서 16 배 선명한 초 고화질 화질 (4K:3,840x2,160 8K:7,680x4,320)과 다채널(10.2 채널 이상) 오디오로 사실감과 현장감을 체험할 수 있는 실감 방송으로 정의하고 있다[6]. 단순히 기존 $\mathrm{HD}$ 방송보다 높 아진 해상도뿐 아니라 TV를 통해 보는 사물이 현실에서 보는 것과 동일한 느낌의 사실감(Sense of reality)과 현 장감(sense of presence)의 증가를 의미한다. 또한 대형 화 된 디스플레이로 넓은 시야각(FOV: field of view)에 의해 뛰어난 사실감과 현장감을 제공하고 있다. 화면이 커지고 밝을수록 화면의 깜박임(flickering)과 영상의 움 직임 열화(motion blur)를 감소시키기 위해 UHDTV 에 서는 영상의 프레임율(frame/sec)을 $60 \mathrm{fps}$ 이상 높일 필 요가 있다. 또한 화면이 커지면 계조(Gradation)가 계단 처럼 보이는 효과가 증대되는 데, 이를 해결하기 위해서 는 비트 심도를 8bit보다는 10bit, 12bits 등으로 높여야 하며 오디오에 있어서는 10.2 채널 이상을 사용하여, 수평 및 수직에서의 서라운드 효과로 어느 방향에서나 실제 현장에서와 같은 음향을 제공해야 한다[7]. 
〈Table 1〉 UHDTV Systems for Audio / Video Signals of a Technical Specification

\begin{tabular}{|c|c|c|c|c|}
\hline \multirow[b]{2}{*}{ Division } & \multicolumn{2}{|c|}{ UHDTV } & \multirow[b]{2}{*}{ HDTV } & \multirow[b]{2}{*}{ 비고 } \\
\hline & $\begin{array}{c}\mathrm{K}(\mathrm{UHD} \\
-1)\end{array}$ & $\begin{array}{c}8 \mathrm{~K}(\mathrm{UHD} \\
-2)\end{array}$ & & \\
\hline $\begin{array}{c}\text { Resolution } \\
\text { (Pixel/frame) }\end{array}$ & $\begin{array}{c}3,840 \times \\
2,160(4 \mathrm{~K})\end{array}$ & $\begin{array}{c}7,680 X \\
4,320(8 \mathrm{~K})\end{array}$ & $\begin{array}{r}1,920 x \\
1,080\end{array}$ & \\
\hline $\begin{array}{l}\text { Frame rate } \\
\text { (frame/sec) }\end{array}$ & \multicolumn{2}{|c|}{$\begin{array}{c}\text { 120,60,60/1.001, } \\
50,30,30 / 1.001,25,24 \\
24 / 1.001\end{array}$} & $30 \mathrm{~Hz}$ & $\begin{array}{c}4 \\
\text { times }\end{array}$ \\
\hline $\begin{array}{l}\text { Bit Depth } \\
\text { (bit/pixel) }\end{array}$ & \multicolumn{2}{|c|}{$24 \sim 36$ bit } & 24bit & $\begin{array}{l}1 \sim 1.5 \\
\text { times }\end{array}$ \\
\hline $\begin{array}{c}\text { Color } \\
\text { sampling }\end{array}$ & \multicolumn{2}{|c|}{$4: 4: 4,4: 2: 2,4: 2: 0$} & $4: 2: 0$ & $\begin{array}{l}1 \sim 2 \\
\text { times }\end{array}$ \\
\hline aspect ratio & $16: 9$ & & $16: 9$ & same \\
\hline $\begin{array}{c}\text { Standard } \\
\text { viewing angle }\end{array}$ & $55^{\circ}$ & $100^{\circ}$ & $30^{\circ}$ & $\begin{array}{c}3.3 \\
\text { times }\end{array}$ \\
\hline $\begin{array}{l}\text { Standard } \\
\text { viewing } \\
\text { distance }\end{array}$ & $1.5 \mathrm{H}$ & $0.75 \mathrm{H}$ & $3 \mathrm{H}$ & Height \\
\hline $\begin{array}{c}\text { audio } \\
\text { channels }\end{array}$ & \multicolumn{2}{|c|}{$10.1 \sim 22.2$} & 5.1 & $\begin{array}{l}2 \sim 4.4 \\
\text { times }\end{array}$ \\
\hline
\end{tabular}

\section{2 표현 범위의 확대와 현장감의 증대}

$4 \mathrm{~K}-\mathrm{UHDTV}$ 의 시청 환경과 및 신호 규격 선정의 가 이드라인에 대한 주관적 화질 평가와 ITU-R BT.500의 권고에 따른 DSIS 방법의 실험 결과(박인경 외, 2012) 시 청 거리가 가깝고 비트 율이 $18 \mathrm{Mbps}$ 로 낮게 책정한 조 건에서도 실험자들은 화질의 차이를 거의 느끼지 못하는 것으로 나타났다[8][9]. 최대 신호 대 잡음비(PSNR) 값이 비쌀수록 현재의 대역폭에서도 충분한 고품질의 전송이 가능하고 컬러 포맷이 같은 비트 율 대비 YUV4:4:4 보다 YUV4:2:0도 충분하다는 것으로 나타나고 있다[9]. UHDTV영상의 색채계(colorimetry)는 더 넓은 색채계를 포함하기 때문에 $\mathrm{HDTV}$ 색역1)이 표현하지 못하는 색 까 지도 표현한다. 결과적으로 실제에 더 가까운 색 재생 능 력을 보여주고 있으며 $\mathrm{HDTV}$ 와 UHDTV의 색채계와 색 표현 범위 대해 $\mathrm{UHD}$ 의 색 표현 범위가 훨씬 넓은 것을 알 수 있다 사실감은 해상도와 밀접한 상관관계가 있다. 각 해상도(angular resolution)가 높아질수록 사실감이 더 좋아지는데, 40-50 $\mathrm{cpd}^{2}$ (cycle per degree) 정도까지는

1) 색역(色域), 컬러 색역(gamut)이란 출력될 수 있는 컬러의 범 위를 말함.
화면의 해상도가 높아질수록 사실감도 함께 높아진다[8]. 현장감은 화면의 크기와 시야각 (viewing angle)에 비례 하며, 2 차원 영상을 통해 느끼는 현장감은 시야각이 약 80 도 부터 100 도 까지 의 범위에서 포화 상태가 된다 [10][17].

\section{3 국내외 서비스 동향과 실험 방송}

국내외 방송사들의 UHDTV서비스 현황을 살펴보면 일본은 NHK주도로 2007년 위성 기반 8K-UHDTV 콘텐 츠 전송 실험에 성공하였다[11][12]. 미국의 경우 2012년 CBS와 NEP Broadcasting과 제휴를 통해 미국 최대 인 기 스포츠 경기 Super Bowl을 UHDTV 시험 방송으로 송출한 데 이어 ESPN, Fox 등이 ⿱ㅡ夫 프로 미식축구(NFL) 2012 시즌 경기 절반 이상을 Sony의 F65 카메라를 통해 $4 \mathrm{~K}$ 영상으로 테스트 하였다. 독일의 Sky Deutschland는 'IBC 2012'를 통해 UHDTV 지원 의사를 표명한 이후 현 재 UHDTV 시험 방송을 위한 채널 확보를 추진 중이다. 프랑스의 경우 2013년 1월부터 EUTELSAT(프랑스 통 신위성 운영 업체)이 DVB-S2/8PSK 방식으로 $4 \mathrm{~K} \mathrm{UHD}$ 위성방송 서비스를 실시 중이고, 미국의 볼티모어에서도 2013년 초 6개월간 DVB-T2 기반으로 $25 \mathrm{Mbps}$ 전송 실 험이 성공적으로 수행되었다[12][13]. 국내의 실험 방송 과 서비스 현황으로는 $\mathrm{KBS}$ 를 중심으로 지상파3사가 2012 년 10월 에서 12월에 지상파 $4 \mathrm{~K}$ 방송의 실험을 실 시하였으며 2013년 5월부터 10월 동안 제2차 실험을 실 시하였다. KBS는 2014년 4월 5일 '2013 2014 KB 국민 카드 프로 농구' 챔피언결정전 3차전을 지상파 방송을 이 용해 $4 \mathrm{~K}$ 60프레임으로 UHDTV 66번 채널(782MHz $788 \mathrm{MHz}$ )을 통해 실시간 중계 방송하였다. 케이블 TV는 2014 년 4월 10일 UHD 전용 채널인 유맥스(UMAX)를 통해 케이블 공통으로 1번(C\&M 33번)으로 본 방송 개시 하였으며 위성 KT Skylife는 2013 년 8 월에 위성에서 $4 \mathrm{~K}$ 방송 실험을 실시. 2014 6월2일 부터 본 방송을 개시 하였다[13].

2) cpd: (cycles per degree)사람의 눈이 하나의 대상을 다른 대 상으로부터 얼마나 상세히 구별할 수 있는지 나타내는 척도 이며, 각 분해능(angular resolution)으로 측정된다. 


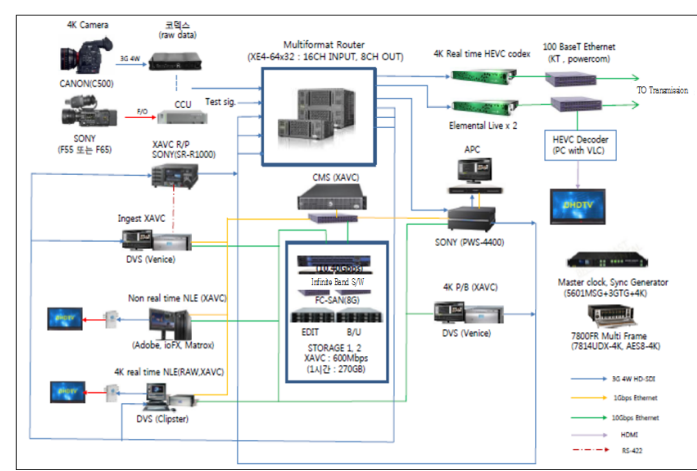

[Fig. 1] KBS UHDTV(4K) Test Broadcasting Net-Work Block Diagram [Source : KBS Technical Research Institute]

\section{$2.44 \mathrm{~K}-\mathrm{UHD}$ 콘텐츠 제작 특성의 변화}

$\mathrm{UHD}$ 영상의 기본적인 기술적 목표는 '대형화된 화면 에서의 자연스러운 영상 표현' 으로 해상도 $(4 \mathrm{~K}, 3840 \mathrm{X}$ 2160 기준)의 증대, 기존 $\mathrm{HD}$ 대비 색역(Color Gamut) 의 증대로 인한 풍부한 색 표현력 증가, 영상의 계조가 $8 \mathrm{bit}$ 에서 $10 \mathrm{bit}, 12 \mathrm{bit}$ 의 증가로 인한 넓은 콘트라스트 표현 으로 압축 할 수 있다. 제작 방식의 차이에서는 $4 \mathrm{~K} \mathrm{Raw}$ 촬영과 D.I작업을 통해 영화와 같은 수준의 고품질 영상 제작이 가능하다. 따라서 $\mathrm{TV}$ 프로그램의 다양성과 상업 성을 제고할 수 있는 기반이 마련되었다고 할 수 있다. 대용량 데이터의 수집, 저장, 편집, 전송 등에서 대용량 데이터를 효율적으로 처리 및 관리하는 사전 기획 단계 의 중요성이 부각되는 등 촬영과 편집의 제작 프로세스 의 변화가 나타나고 있다. 또한 장르 및 소재의 변화 측 면에서도 기존에 담아내기 힘들었던 마이크로 촬영, 색 상의 다양함을 담아낼 수 있는 소재 등이 강점을 가질 수 있을 것으로 분석되고 움직임이 많고 현장감이 중요시되 는 스포츠 제작 등 프로그램 제작의 차별성을 드러내 줄 것으로 기대된다. 반면 대형화면에서 많은 영상 정보를 제공하기 때문에, 초기에는 현재 트렌드(Trend)화된 셀 레브리티(Celebrity)효과로 매우 선명한 영상이 출연자들 의 화장이나 세트, 소품 등 미장센 요소에 다소 부담이 되거나, 젊은 층의 음악 프로그램 등 화면전환이 빠른 영 상에서의 시청 불편 등의 이슈가 제기될 것으로 분석 되 고 있다[14].

\section{3. 연구 문제 및 연구 방법}

\section{1 연구 문제}

본 연구에서는 단순히 $\mathrm{HDTV}$ 해상도(1920X1080)가 $4 \mathrm{~K}-\mathrm{UHDTV}$ 해상도 $(3840 \times 2160)$ 로 커지는 카메라 해상 도의 증가를 의미하는 협의의 개념이 아니라 $4 \mathrm{~K}-\mathrm{UHDTV}$ 콘텐츠 제작에 관한, 기획, 미디어 파일 관 리, 카메라, 렌즈의 종류와 특징, 레코딩 장비와 압축 포 맷 등의 변화에 따른 $\mathrm{UHD}$ 콘텐츠 제작에 관한 전반적 워크플로우의 방향성에 대해 알아본다. $4 \mathrm{~K}-\mathrm{UHDTV}$ 제 작 전문가 집단의 Delphi를 통한 $\mathrm{UHD}$ 콘텐츠 제작에 있 어 중요하게 고려해야 할 사항을 정립하여 연구 문제의 항목으로 분류하였다. 또한 분류된 항목을 상위 계층과 하위 계층으로 분류하여 상호 중요도를 평가하여 $4 \mathrm{~K}-\mathrm{UHDTV}$ 콘텐츠 제작의 활성화를 위한 중요 항목 도 출과 상호 중요도를 비교를 하고자 한다.

\section{[연구 문제]}

$4 \mathrm{~K}-\mathrm{UHDTV}$ 콘텐츠 제작워크프로우의 중요 항목을 도출하고 $\mathrm{AHP}$ 분석을 통한 $4 \mathrm{~K}-\mathrm{UHDTV}$ 콘텐츠 제작워 크프로우의 상호 중요도를 비교한다.

\section{2 연구방법}

델파이 기법은 1948 년 미국의 RAND연구소에서 개발 되어 현재의 상태에 대한 일반화, 표준화된 자료가 부족 한 경우 전문가적인 직관을 객관화하는 예측의 방법으로 사용되고 있다. 연구의 예측 조사의 방법으로 사용되는 델파이 기법은 다수의 전문가의 의견을 표준화와 비표 준화 도구를 활용하여 수회에 걸쳐 피드백(feedback)시 켜 그들의 의견을 수렴하고 합의된 내용을 얻는 소위 전 문 집단적 사고를 통하여 체계적으로 접근하는 일종의 예측에 의한 정책 분석 방법이라고 볼 수 있다[15]. $4 \mathrm{~K}$ 콘 텐츠 제작에 있어 기존 제작 방식과 차별화 되고 중요하 게 고려해야 할 대상으로 현재 $4 \mathrm{~K}$ 콘텐츠 제작 현장에 있는 기술, 카메라, 편집 등 전문가 집단 10 명의 인터뷰를 통해 연구 문제인 $4 \mathrm{~K}-\mathrm{UHDTV}$ 콘텐츠 제작워크프로우 의 중요 항목을 도출 하고 계층적 비교를 $(\mathrm{AHP})$ 위한 상 위 요소와 하위 요소를 분류 하였다. 1 차 심층 인터뷰 결 과를 정리, 분류하여 2차 피드백을 통해 중요 항목을 확 정 하였다. 계층적 분석 방법 $(\mathrm{AHP})$ 은 여러 대안들 중에 
선택을 용이하게 하 기 위해서 T.Satty(1977)가 고안한 계층 분석 방법이다. $\mathrm{AHP}$ 는 의사 결정 요소들의 속성과 그 측정 척도가 다양한 다 기준 의사 결정 문제에 효과적 으로 적용되어 의사 결정자가 선택할 수 있는 여러 가지 대안들을 체계적으로 순위 화 시키고 그 가중치를 비율 척도로 도출하는 방법을 제시한다. 본 연구에서는 $4 \mathrm{~K}-\mathrm{UHD}$ 제작을 위한 워크플로우의 요인들에 대한 상대 적 중요도를 분석하기 위하여 $\mathrm{AHP}$ 계층화 분석 모형을 적용하였다. 계층적 분석 과정을 위한 일반적 절차는 의 사 결정 목표 설정, 의사 결정 요인 도출, 전문가 선정, 데 이터 수집, 분석으로 구분된다. 먼저 의사 결정 문제를 계 층화한다. 이것은 주어진 의사 결정 문제를 상호 관련된 의사 결정 요소들로 계층화하여 문제를 분리하는 과정이 다. 그런 다음, 각 요소들 간에 이원 비교하는 것으로서 요소들을 두개씩 뽑아 이원 비교를 통해 요소들 간 상대 적 중요도를 평가 한다. 세 번째는 가중치를 추정하는 과 정에서 이원 비교를 행한 후에는 각 계층에 대하여 비교 대상 평가 요소들이 갖는 상대적인 가중치를 추정한다. 네 번째는 논리적인 일관성을 검증하는 단계로 이원 비 교를 통한 요소들에 대한 평가 결과에 대하여 일관성 비 율이 0.1 이하일 경우 일관성 있는 설문으로 판단한다. 일 관성은 $\mathrm{CR}$ (Consistency Ratio)를 이용하여 검증한다. 즉 $\mathrm{CR}=\mathrm{CI} / \mathrm{RI}$ 이다. 일관성이 완벽할 경우 “0”이 되며, 일 관성이 나빠질수록 그 값이 커진다. Saaty는 정확도가 “0.1” 보다 작은 경우에만 서수 적 순위에 무리가 없는 신 뢰할 수 있는 결과라고 한다. AHP단계의 마지막은 하위 계층에 있는 평가 요소들의 가중치를 구하기 위해서 각 계층에서 계산된 평가 기준들의 가중치를 종합하는 과정 이다[15][16]. 본 연구에서는 $4 \mathrm{~K}-\mathrm{UHD}$ 콘텐츠 제작에 관 한 핵심적 워크플로우가 적립되지 않고 기존의 제작 방 식을 답습하는 프로세스에서 초기 $\mathrm{UHD}$ 콘텐츠 제작 워 크프로의 핵심 요소에 대한 중요도를 분석하기 위한 가 장 적합한 방법으로 $4 \mathrm{~K}-\mathrm{UHDTV}$ 제작을 위한 중요 항 목의 Delphi 분석을 참고하여 $4 \mathrm{~K}-\mathrm{UHDTV}$ 콘텐츠 제작 워크플로우의 주요 요인을 설정하였다. 상위 요인으로는 콘텐츠 제작 기획, 미디어 파일 관리, 제작 장비의 선택과 운영으로 분류하였으며 다시 하위 계층 3 개씩 9 개로 분 류하여 상호 중요성을 측정하였다.
〈Table 2〉 Model of Hierarchical Configuration factors

\begin{tabular}{|c|c|}
\hline $1^{\text {st }}$ Layer & $2^{\text {nd }}$ Layer \\
\hline \multirow{3}{*}{$\begin{array}{c}\text { Content } \\
\text { Creation Plan }\end{array}$} & Content Selection and Concentration \\
\hline & The application of planning and OSMU \\
\hline & UHD making role and training STAFF \\
\hline \multirow{3}{*}{$\begin{array}{l}\text { Media file } \\
\text { management }\end{array}$} & Media Management \\
\hline & Planning and Operational Metadata \\
\hline & Planning and CGI VFX \\
\hline \multirow{3}{*}{$\begin{array}{l}\text { Selection and } \\
\text { operation of } \\
\text { production } \\
\text { equipment }\end{array}$} & Select the Camera \\
\hline & Selection and operation of the Lens \\
\hline & Selection and operation of the storage device \\
\hline
\end{tabular}

\section{4 상위 계층 및 하위 계층 요인 정의}

\subsection{1 콘텐츠 제작 기획}

가. 콘텐츠 장르별 선택과 집중

초기의 미디어 발전 과정에서는 기술적 발달과 장비 의 성능과 워크플로우가 결정적인 역할을 하고 있다. $4 \mathrm{~K}-\mathrm{UHDTV}$ 콘텐츠도 예외이지는 않다. 미래부의 $\mathrm{UHD}$ 공동 펀드 제안 요청서에서도 $\mathrm{UHD} 10$ 분물 제작에 7 억5 천만 원의 비용에 4 개월 소요, 50 분물은 11 억 원 이상 5 개월이 소요되는 것으로 보고되고 있을 정도로 시간과 비용, 제작 과정도 해결해야 할 문제가 많다[17]. 이러한 맥락에서 $4 \mathrm{~K}-\mathrm{UHDTV}$ 가 상용화되기 까지는 여러 가지 해결해야 할 문제가 있다. 전송 방식의 표준화, 지상파의 주파수 문제 이외에도 $4 \mathrm{~K}-\mathrm{UHDTV}$ 의 장르 선택도 같은 맥락에서 적용하여야 한다. 스포츠 중계나 대형 오락 쇼 등은 기술적 안정성과 장비의 보급이 우선시 되어야 한 다. 그러나 비교적 단순한 시스템으로 제작 할 수 있는 고품격 다큐멘터리나 드라마 위주의 $4 \mathrm{~K}-\mathrm{UHDTV}$ 콘텐츠 의 제작이 초기 콘텐츠 시장의 활성화를 위한 대안이 될 수 있다.

\section{나. 기획과 $\mathrm{OSMU}$ 의 적용}

$\mathrm{UHD}$ 영상 뿐 아니라 $2 \mathrm{~K}$ 혹은 $\mathrm{HD}$ 영상에서도 사전에 어떠한 포맷으로 녹화나 촬영을 해야 할지를 결정하는 것이 가장 중요하고 먼저 선결해야 할 과제이다. 한번 제 작된 콘텐츠를 다양한 영상 포맷으로의 변화를 통해 여 러 종류의 Device 에서의 활용이 가능하기 때문이다. 이 렇듯 제작 하고자 하는 콘텐츠의 시간과 비용을 고려하 여 어떤 Device 에 어떻게 서비스를 해야 할 것인가를 먼 
저 정하고 적절한 Frame 과 해상도를 지원하는 장비를 선택해 운영하는 것은 기획 단계의 첫 출발점이 될 것이 다. $\mathrm{UHD}$ 콘텐츠를 제작하기 위해서는 사전 기획과 시장 조사, 장비의 선택, 미디어의 저장에 관한 선택, 편집에 대한 이슈, 그리고 $\mathrm{CG}$ 의 위치 및 종류에 대한 선택 등 매 우 다양하고 민감한 사항이 수반 되어야 한다. 또한 제작 된 콘텐츠를 유통, 배급하는 전반적인 과정에서도 신중 한 기획과 접근이 $\mathrm{UHD}$ 영상의 제작 기간에 걸리는 시간 과 예산을 효율적으로 통제가 가능하다. 현실적으로 $\mathrm{UHD}$ 콘텐츠와 $\mathrm{HD}$ 콘텐츠를 동시에 제작해야 하는 상황 에서는 이 둘의 서비스 포맷에 맞게 제작 과정과 기획도 병행해야 한다. 잘못된 코덱의 선택으로 촬영을 포기하 거나 다시 해야 하는 문제가 될 수 있다. 뿐만 아니라 미 디어의 저장과 편집에 있어서도 기존의 Off-Line 편집 개념으로 접근하면 훨씬 더 많은 시간과 비용이 추가 될 수 있다. 그밖에도 모니터링 시스템이나 파일의 관리 등 을 소홀히 한다면 $\mathrm{UHD}$ 촬영 자체의 큰 부담으로 이어질 수 있다. 이러한 사전 기획 단계에서의 중요한 역할이 $\mathrm{UHD}$ 영상의 원활한 제작과 완성도를 높일 수 있다.

\section{다. $\mathrm{UHD}$ 제작 $\mathrm{STAFF}$ 간의 역할과 트레이닝}

$\mathrm{HD}$ 보다 $\mathrm{UHDTV}$ 는 고선명도 화질 구현이 용이하기 때문에 제작 과정에서의 모니터링 문제, 컨버팅 문제, 파 일의 저장과 보관 등의 운영 적 문제와 제작 과정에서의 카메라 포커스나 파일 포맷의 결정 등 여러 가지 기술적 인 오류 요소들이 쉽게 발견됨을 고려하였을 때 장비뿐 만 아니라 숙련된 전문가 교육이 필요하다. 3D 입체 영상 콘텐츠 제작의 초창기에 스테레오 그래퍼 양성과 역할론 에 관한 논란이 있었다. $\mathrm{UHD}$ 콘텐츠 제작에 있어서도 기 술적으로나 운영 적으로 특화되고 전문적인 인력 양성과 체계적인 준비, 교육, 경험의 과정이 필수적으로 동반 되 어야 한다.

\subsection{2 파일 포맷과 메타 데이터}

$\mathrm{UHD}$ 영상의 레코딩에서 대부분 지원되는 일반적인 파일 기반의 카메라나 레코딩 장비는 지원하는 고유의 코덱3)이 있으며 이러한 코덱을 편집기에서 읽어 들이면

3) 코덱은 캡쳐링 및 저장되기 위해 필요한 데이터의 전체 양을 줄이기 위해 레코딩 장치를 사용한 압축/비압축 알고리즘을 뜻하며 파일 유형은 해당 코덱이 그 안에 내재된 캐리어
된다. 이 과정에서 레코딩된 코덱을 지원하지 않는다면 별도의 호환이 가능한 컨버팅 작업과 PLUG-IN 프로그 램을 설치하여 해결해야 한다. 카메라와 레코딩 회사별 로 고유의 코덱과 양식이 존재하므로 편집이나 미디어 관리를 담당하는 STAFF 은 호환 가능한 파일의 워크플 로우를 잘 숙지하고 운영해야 한다. 대부분 현장에서 레 코딩된 파일은 통상의 편집 시스템에서 지원하는 코덱으 로 통일하여 운영하는 것이 일반적이다.

가. 미디어 관리

$\mathrm{UHD}$ 제작에 있어 파일 기반 시스템에서 미디어의 관 리와 운영은 제작 현장과 후반 작업 전반적인 워크프로 우 관리가 중요하다. 과거의 Tape 기반에서는 촬영 현장 에서 넘겨받은 Tape을 후반 처리나 편집 과정을 거쳤으 나 파일 기반 시스템에서는 촬영 현장에서 부터의 미디 어 관리가 최종 유통 단계까지 연계되어 이어지기 때문 이다. 촬영 현장에서의 카메라 종류에 따른 여러 종류의 파일 포맷이 혼재되는 경우가 종종 발생한다. 미디어 관 리는 전체 콘텐츠 관리에 매우 중요한 요인으로 작용하 며 이에 따라 적용되는 워크프로우 또한 사전에 정확한 계획과 체계적인 관리가 필요하다.

\section{나. 메타데이터 계획과 운영}

메타데이터는 의미적으로 다른 원 데이터에 대한 정 보를 일컫는다. 메타데이터는 이미지 해상도, Bit, 심도, 렌즈 세팅, 장소, 혹은 수집 이후의 단계에서 누군가 이미 지를 활용하기 위해 유용할 수도 있을 그 어떤 사항에 대 한 디테일을 제공할 수 있다. 일반적으로, 풍부한 메타데 이터는 포스트 프로덕션이 더 신속히 이루어질 수 있도 록 하며 콘텐츠가 분산되거나 아카이브(archive)될 때 그 콘텐츠의 적절성을 유지할 수 있다. 메타데이터는 미디 어 자산(Asset)을 생성하고 Archiving 과 제작워크프로 우 에 활용 가능 할 뿐 아니라 그 밖의 용도로도 사용 범 위가 무궁무진하다. $\mathrm{UHD}$ 제작 과정에서 자동적으로 생 성된 메타데이터는 능률적인 프로세싱을 위해 필요한 중 요 정보를 포함하고 있으며 그러한 데이터 유형으로는 타임 코드, 데이터, 카메라 모델과 시리얼 넘버, 초점 길 이, $\mathrm{UMID}$ (혹은 기타 고유 식별 데이터) 등으로 구분 할 수 있다. 또한 사용자 정의 메타데이터로는 Clip ID, 현지

(carrier) 혹은 래퍼(wrapper) 포맷을 의미한다. 
촬영 장소, 카메라 $\mathrm{ID}$ (멀티 카메라 샷을 구분하기 위함), 탤런트 구분, 프로듀서나 촬영감독 구분 등이다. 메타데 이터 역시 촬영을 마친 후에 파일 기반 자원으로 추가 될 수 있다. 편집에 대한 인터페이스를 제공하거나 메타데 이터를 첨부하거나 오리지널 파일을 보관하는데 활용할 수 있다. Archived된 복사본이나 다양한 유통을 통한 콘 텐츠의 재활용을 위해서도 메타데이터의 통합 유지 관리 가 필요하다. 풍부한 메타데이터를 획득하고 활용하는 데에는 많은 시간과 노력을 기울여야 하는 번거로움이 있지만 $\mathrm{UHD}$ 제작워크프로우 에서의 고품질의 콘텐트를 제작하기 위해 반드시 필요한 요소이다.

\section{다. $\mathrm{VFX}$ 의 기획과 $\mathrm{CGI}$}

여러 가지 경우에 $4 \mathrm{~K}$ 영상으로 직접 촬영하지 못하거 나 보다 시각적으로 효과를 주고 싶을 때는 CGI 작업을 통해 VFX 작업을 거쳐 원하는 입체 영상을 제작 할 수 있다. 보통 CGI 는 (Computer-generated imagery)컴퓨 터 그래픽스 분야의 응용이며, 더 구체적으로 말해 영화, 텔레비전 프로그램, 광고, 시뮬레이터, 시뮬레이션, 인쇄 매체의 특수 효과를 위한 3차원 컴퓨터 그래픽스를 말한 다. 특수 효과는 보통 진짜같이 보이게 만드는 환경을 조 성해야 하지만 촬영하기에 위험하거나 비용이 많이 들거 나 현실 적으로 불가능한 경우 라이브 액션 동영상을 $\mathrm{CGI}$ 등과 통합할 때 함께 사용되는 것을 통칭 $\mathrm{VFX}^{4}$ 작 업이라고 한다. CGI 를 구현하기 위해서는 동영상, 사진, 서적, 의사자 문등 여러 가지 자료를 취합하고 정리하여 작가와 CGI 작업자가 자료를 공유하여 정밀한 스토리 보 드를 구성, 카메라의 동선, 레이아웃, 타이밍 등을 표시 하고 프리비쥬얼 단계를 거쳐 보다 실사와 $\mathrm{CG}$ 가 합성 되 었을 때의 상태를 미리 확인해 보는 과정도 필요하다.

\subsection{3 제작 장비의 선택과 운영}

가. 카메라의 선택

$\mathrm{UHD}$ 영상의 촬영과 카메라의 선택에 있어 고려해야 할 사항으로 먼저 어떠한 프레임 레이트를 지원하며 해 상도에 대한 특성은 기본적으로 고려되어야 한다. 첫째 단일 카메라의 선택과 멀티 카메라의 선택이다. 단순히 1 대의 $4 \mathrm{~K}-\mathrm{UHD}$ 카메라를 이용한 제작과 여러 대의 카메라

4) 시각 효과(視覺效果) 또는 비주얼 이펙트(visual effects, visual $\mathrm{F} / \mathrm{X}, \mathrm{VFX}$ )
를 이용하여 동시에 제작하는 방식을 구분하여 선택해야 한다. 두 번째로 카메라가 지원하는 셔터(Shutter)의 종 류와 특성을 고려해야 한다. 통상 글로벌 셔터(Global Shutter) 와 롤링셔터(Rolling Shutter)로 구분 되며 촬 영하고자 하는 피사체의 특징에 맞는 셔터를 지원하는 카메라의 선택이 중요하다. 일반적으로 롤링셔터(rolling shutter)은 $\mathrm{CMOS}$ 를 사용 순차적인 이미지를 읽는 방식 이며 글로벌 셔터(global shutter)는 $\mathrm{CCD}$ 를 사용, 프레임 단위로 정보를 읽는 방식이다. 이러한 두 가지 shutter 방 식으로 인해 카메라의 움직임 특히 panning을 할 때 보 여 지는 그림의 차이가 발생하기 때문이다. 글로벌 셔터 에 비해 롤링셔터의 그림이 스큐(skew)즉 기울어짐 현상 이 발생한다.

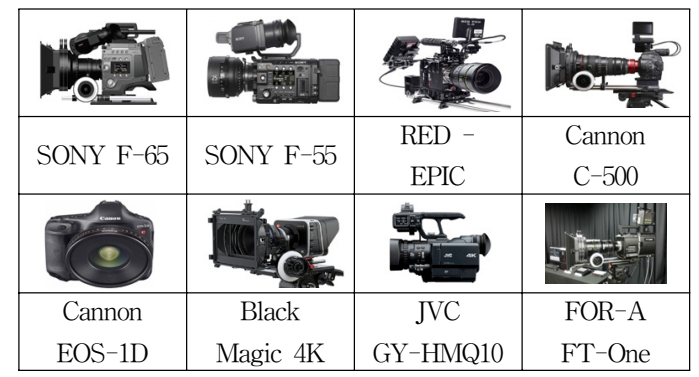

[Fig. 2] Types of $4 \mathrm{~K}$ camera

나. 렌즈의 선택과 운영

카메라와 결합하여 사용하는 렌즈의 선택은 카메라의 선택만큼이나 중요하다. 카메라의 종류와 특성에 맞는 렌즈의 선택은 편안하고 안정적인 $\mathrm{UHD}$ 영상 제작에 있 어 선택의 신중함을 요하고 있다. 줌렌즈(Zoom Lens)와 단 렌즈(Prime Lens)의 선택과 카메라에 장착되는 마운 트(Mount) Type 의 선택도 신중을 기해야 한다. 사용하 고자 하는 마운트가 다른 기종의 카메라와 결합이 가능 한지 여부에 따라서 다양한 종류의 $\mathrm{UHD}$ 카메라를 사용 할 수 있기 때문이다. 렌즈의 Zoom, 조리개(IRIS), 포커 스(Focus)를 컨트롤 할 수 있는 모터 장치의 선택 과정에 서도 렌즈의 Type 과 기능을 고려해야 한다. 기계적 장 치로 컨트롤 할 것인지 또는 전자적 장치로 컨트롤 할 것 인지 도 고려해야 할 대상이다. 기존 B4 마운트 렌즈를 어떻게 카메라에 적용 시킬 것인가에 대한 문제와 PL 마 운트의 줌 배율 문제 등으로 초기 스튜디오 적용에 어려 움이 있다. 


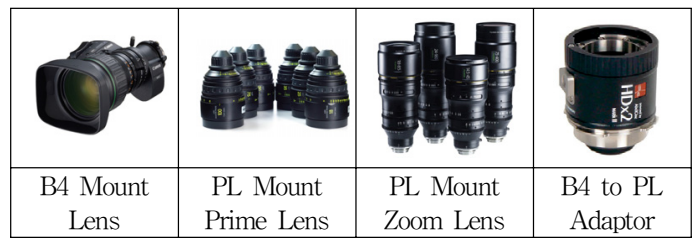

[Fig. 3] Type of lens

다. 저장과 장치의 선택과 운영

현재의 $\mathrm{UHD}$ 콘텐츠 제작 현황을 살펴보면 파일 제작 시스템이 기본 주류를 이루고 있다. 제작하고자 하는 콘 텐츠의 종류와 특성에 따라 HDD Type 레코더나 $\mathrm{SSD}^{5}$ ) Memory Type 레코더로 분류되어 있는 녹화 시스템을 사용하면 된다. 이동성이나 순발력이 있다면 부피가 작 고 배터리로 운영되는 녹화기를 사용하거나 고정된 장소 에서 고화질을 원한다면 보다 성능이 좋은 레코더를 선 택하면 될 것이다. 통상의 $4 \mathrm{~K}-\mathrm{UHD}$ 편집에서는 Apple 의 Final cut pro 나 Avid 시스템 또는 Adobe 사의 프리 미어 시스템을 사용하는 NLE 시스템이 주류를 이루고 있으며 파일로 녹화된 코덱(CODEC)이 편집 시스템에서 바로 지원한다면 작업의 시간과 효율을 훨씬 줄여 줄 수 있다. 이러한 미디어의 저장과 편집까지의 종합적인 관 리와 워크플로우를 통합적으로 관리하며 운영하는 것이 중요하다.

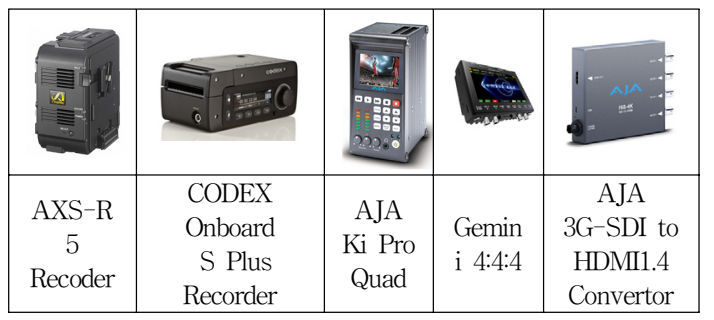

[Fig. 4] 4K-File Storage

\section{4. 설문조사 분석}

\subsection{Delphi를 통한 전문가 심층 인터뷰}

$4 \mathrm{~K}-\mathrm{UHD}$ 콘텐츠 제작을 하고 있는 기술, 카메라, 편

5) 솔리드스테이트 드라이브(solid-state drive, SSD)보통 디램 휘발성 메모리나 일차 낸드 플래시 비휘발성 메모리로 이루 어져 있다
집, 장비 관련, 종사 자등 현장 제작 전문가를 중심으로 $4 \mathrm{~K}-\mathrm{UHD}$ 콘텐츠 제작 활성화를 위한 워크플로우의 중요 항목에 대한 심층 인터뷰를 통해 상위 계층의 요소와 하 위 계층의 요소를 다음 표와 같이 분류 하였다.

〈Table 3〉 Hierarchical classification model $4 \mathrm{~K}-\mathrm{UHD}$ content creation workflow analysis

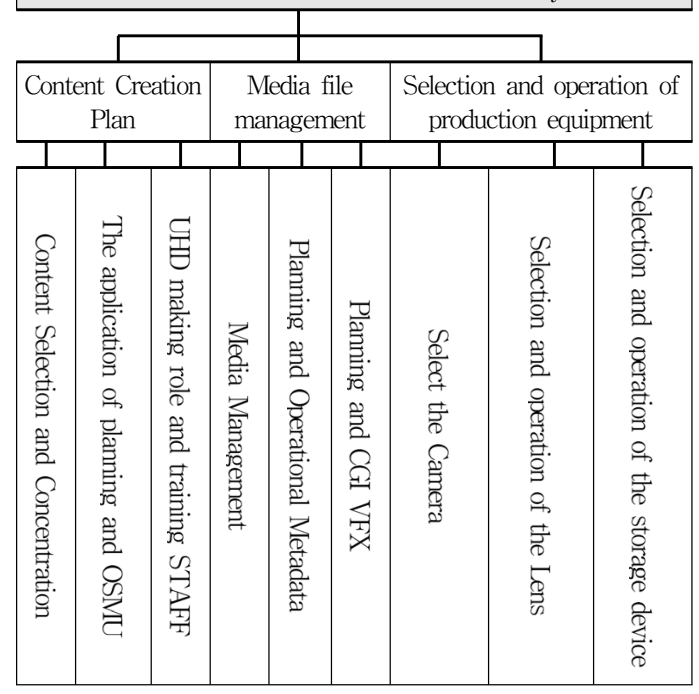

\section{2 설문 모집단}

연구 모형의 검증을 위해 국내 UHDTV 관련 제작 분 야 전문가를 대상으로 지상파 방송사의 $4 \mathrm{~K}$ 제작 실무 팀 과 연구소, 관련 업계 전문가, 그리고 학계의 교수나 연구 원을 대상으로 설문을 진행하였다. 조사 방법은 각 관련 전문가를 대상으로 전자메일과 면대면 설문조사를 실시 하였다 총30명의 전문가가 설문에 참여하였고 이중에서 개인별 답변의 일관성 지수 $(\mathrm{CI})$ 가 $<0.1$ 인 최종 30 명의 답 변을 채택하여 연구를 진행하였다.

\section{〈Table 4〉 Distribution of Experts Population}

\begin{tabular}{|c|c|c|c|}
\hline Classification & $\begin{array}{c}\text { Broadcast } \\
\text { areas }\end{array}$ & $\begin{array}{c}\text { Broadcast } \\
\text { areas }\end{array}$ & Total \\
\hline Population & 20 & 10 & 30 \\
\hline Distribution & $66.7 \%$ & $33.3 \%$ & $100 \%$ \\
\hline
\end{tabular}

\section{3 설문 방법}

설문조사 방식은 종축과 횡축의 평가 항목을 이원 비 교하여 종축의 평가 항목이 횡축의 평가 항목에 비해 상 
대적으로 어느 정도 중요한지 또는 어느 정도 비효율적 인지를 평가 기준에 따라 $1,2,3,4,5$ 또는 $1 / 2,1 / 3,1 / 4$, $1 / 5$ 까지의 척도를 기입하도록 하였다.

\section{〈Table 5〉 Comparison Measurements between Components}

\begin{tabular}{|c|c|}
\hline $\begin{array}{c}\text { Numerical } \\
\text { values }\end{array}$ & Definition \\
\hline 1 & Equally important, or if preferred(equal) \\
\hline 2 & $\begin{array}{l}\text { More important, or if slightly } \\
\text { preferred(moderate) }\end{array}$ \\
\hline 3 & Strongly important, or it preferred(strong) \\
\hline 4 & $\begin{array}{c}\text { Very strongly important, or it preferred(very } \\
\text { strong) }\end{array}$ \\
\hline 5 & Extremely important, or it preferred(extreme) \\
\hline Reciprocals & $\begin{array}{l}\text { It is used to reflect that the second option is } \\
\text { excellent as compared to the first alternative. }\end{array}$ \\
\hline
\end{tabular}

\section{4 분석 결과}

\subsubsection{1차 계층 분석 결과}

1 차 계층 요인은 콘텐츠 제작 기획 측면, 미디어 파일 관리 측면, 제작 장비의 선택과 운영 측면의 3 가지 요인 으로 분류하여 상대적 중요도를 분석하였다. 분석 결과 제작 장비의 선택과 운영 측면이(0.522))으로 가장 중요 하게 나타났고 다음으로 미디어 파일 관리 측면이(0.344), 콘텐츠 제작 기획 측면이(0.134)로 나타났다.

$\langle$ Table 6〉 Analysis result of 1st Layer

\begin{tabular}{|c|c|c|}
\hline Classification & $\begin{array}{c}\text { Degree of } \\
\text { importance }\end{array}$ & CI \\
\hline Content Creation Plan & 0.134 & \multirow{2}{*}{0.0526} \\
\cline { 1 - 2 } Media file management & 0.344 & \\
\hline $\begin{array}{c}\text { Selection and operation } \\
\text { of production equipment }\end{array}$ & 0.522 & \\
\hline
\end{tabular}

\subsubsection{2차 계층 분석 결과(1차 계층 하위 부문별)}

첫째, 1 차 계층 요인의 콘텐츠 제작 기획 분야의 2 차 계층의 상대적 중요성 분석 결과 $\mathrm{UHD}$ 제작 $\mathrm{STAFF}$ 간 의 역할과 트레이닝이 (0.545), 콘텐츠 장르별 선택과 집 중이(0.310), 기획과 OSMU의 적용이(0.145)순으로 나타 났다.
〈Table 7〉 Analysis result of 2 nd Layer of Content Creation Plan

\begin{tabular}{|c|c|c|}
\hline Classification & $\begin{array}{c}\text { Degree of } \\
\text { importance }\end{array}$ & CI \\
\hline Content Selection and Concentration & 0.310 & \\
\cline { 1 - 2 } $\begin{array}{c}\text { The application of planning and } \\
\text { OSMU }\end{array}$ & 0.145 & \multirow{2}{*}{0.0284} \\
\cline { 1 - 2 } $\begin{array}{c}\text { UHD making role and training } \\
\text { STAFF }\end{array}$ & 0.545 & \\
\hline
\end{tabular}

둘째, 1 차 계층 요인의 미디어 파일 관리 분야의 2 차 계층의 상대적 중요성 분석 결과 미디어 관리가(0.519), $\mathrm{VFX}$ 의 기획과 $\mathrm{CGI}(0.322)$, 메타데이터 계획과 운영 (0.159)순으로 나타났다.

\section{〈Table 8 > Analysis result of 2 nd Layer of Media file management}

\begin{tabular}{|c|c|c|}
\hline Classification & $\begin{array}{c}\text { Degree of } \\
\text { importance }\end{array}$ & CI \\
\hline Media Management & 0.519 & \multirow{2}{*}{0.0529} \\
\cline { 1 - 2 } Planning and Operational Metadata & 0.159 & \\
\hline Planning and CGI VFX & 0.322 & \\
\hline
\end{tabular}

셋째, 1 차 계층 요인의 제작 장비의 선택과 운영 분야 의 2 차 계층의 상대적 중요성 분석 결과 저장 장치의 선 택과 운영(0.449), 렌즈의 선택과 운영(0.373), 카메라의 선택(0.178)순으로 나타났다.

〈Table 9〉 Analysis result of 2nd Layer of Selection and operation of production equipment

\begin{tabular}{|c|c|c|}
\hline Classification & $\begin{array}{c}\text { Degree of } \\
\text { importance }\end{array}$ & CI \\
\hline Select the Camera & 0.178 & \\
\cline { 1 - 2 } Selection and operation of the Lens & 0.373 & \multirow{2}{*}{0.000} \\
\cline { 1 - 2 } $\begin{array}{c}\text { Selection and operation of the storage } \\
\text { device }\end{array}$ & 0.449 & \\
\hline
\end{tabular}

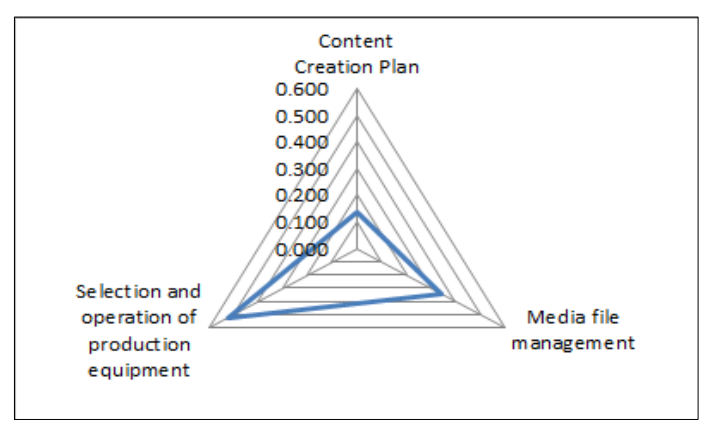

[Fig. 5] Relative importance between the evaluation Factors 


\subsubsection{2차 계층 평가 항목 간 상대적 중요도}

2 차 계층 간의 9 개 요인의 종합 분석 결과, 채택된 30 명 전문가들의 일관성 지수 $(\mathrm{CI})$ 는 0.1 이하로 분포되었으 며 각 문항별 답변의 기하 평균값을 도출하고 9 개 하부 요인에 대한 우선순위 분석하였다. 그 결과, 상대적으로 가장 중요한 요인으로 저장 장치의 선택과 운영 부문이 선택되었으며, 그 다음이 렌즈의 선택과 운영 그리고 $\mathrm{VFX}$ 의 기획과 $\mathrm{CGI}$ 의 순으로 중요하게 판단하는 것으 로 나타났다.

\section{〈Table 11〉 Relative importance between the evaluation Factors}

\begin{tabular}{|c|c|c|}
\hline In terms of evaluation & $\begin{array}{c}\text { Relative } \\
\text { importance }\end{array}$ & Ranking \\
\hline $\begin{array}{c}\text { Content Selection and } \\
\text { Concentration }\end{array}$ & 0.065 & 8 \\
\hline $\begin{array}{c}\text { The application of planning and } \\
\text { OSMU }\end{array}$ & 0.049 & 9 \\
\hline $\begin{array}{c}\text { UHD making role and training } \\
\text { STAFF }\end{array}$ & 0.117 & 4 \\
\hline Media Management & 0.116 & 5 \\
\hline Planning and Operational Metadata & 0.065 & 7 \\
\hline Planning and CGI VFX & 0.106 & 6 \\
\hline $\begin{array}{c}\text { Select the Camera } \\
\text { Selection and operation of the Lens }\end{array}$ & 0.130 & 3 \\
\hline $\begin{array}{c}\text { Selection and operation of the } \\
\text { storage device }\end{array}$ & 0.163 & 2 \\
\hline
\end{tabular}

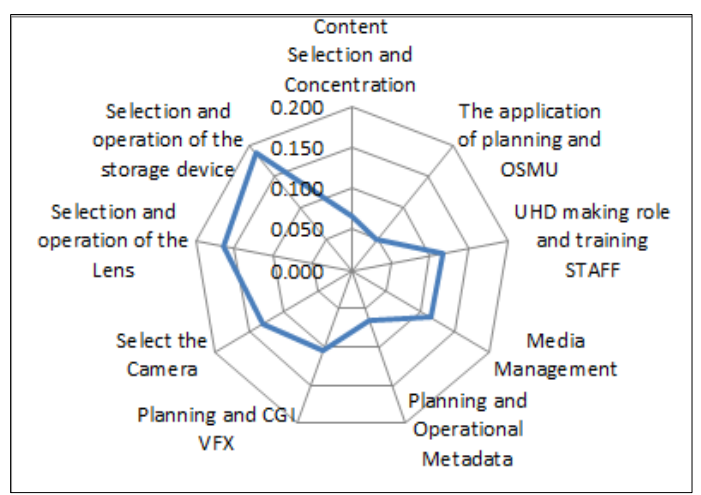

[Fig. 6] Relative importance between the evaluation Factors

\section{$4.54 \mathrm{~K}-\mathrm{UHD}$ 콘텐츠의 실시간 제작 방향 제시}

현재의 $4 \mathrm{~K}-\mathrm{UHD}$ 콘텐츠의 대부분이 $4 \mathrm{~K}$ 카메라로 촬 영된 영상을 Raw File 형태로 저장하여 후반 작업에서 색 보정 및 D.I6) 작업을 통해 초고 해상도 콘텐츠로 가공 되고 있다[19]. 일반적으로 $4 \mathrm{~K}-\mathrm{UHDTV}$ 콘텐츠 제작의 워크플로는 파일 형태의 출력을 원하는 코덱으로 변환 하여 NLE편집기와 D.I Tool을 거쳐 Master 과정을 거치 는 프로세스가 일반적이다. 실시간 $4 \mathrm{~K}-\mathrm{UHDTV}$ 의 서비 스를 위해서는 실시간 $4 \mathrm{~K}$ 영상의 획득, 실시간 PGM 생 성과 전송 등의 제작 프로세스가 구현 되어야 한다. 2014 년 미국 $\mathrm{NAB}$ 에서 열린 방송 장비 전시회에서는 $\mathrm{SONY}$ 와 Cannon사 등에서 기존 $4 \mathrm{~K}$ 카메라에 무 압축 전송 엔 코더를 이용 광회선 으로 전송한 다음 $4 \mathrm{~K}$ 스위칭을 통한 $\mathrm{PGM}$ (Program) 송출이 가능한 모델을 선보였다. Sony 가 제시하는 $4 \mathrm{~K}-\mathrm{UHDTV}$ 콘텐츠 제작 워크플로우를 보 면 새로운 XAVC 코덱은 MPEG-4 AVC/H.264 Level 5.2 압축 기반으로 $4096 \times 2160$ 또는 $3840 \times 2160$ 해상도에 최대 60p 까지 지원하며, $\mathrm{HD}(1920 \times 1080)$ 해상도에서는 최대 $180 p$ 까지 지원한다. 뿐만 아니라 8/10/12 비트 샘 플링 및 4:2:0, 4:2:2, 4:4:4의 컬러 샘플링을 지원한다.[20] 전체 Live 제작의 흐름에서도 SMPTE 규격의 광케이블 을 통한 $4 \mathrm{~K}$ 라이브 신호가 전송이 되고, 4 가닥의 $3 \mathrm{G}-\mathrm{SD}$ I7) 형태로 $4 \mathrm{~K}$ 라이브 신호를 실시간 영상 스위칭을 하 게 된다[20][21]. 이러한 프로세스는 현재 $\mathrm{HD}$ 스튜디오 제 작이나 중계 제작과 같은 형태의 실시간 콘텐츠 생산을 가능케 하고 있다. 워크프로우 하위 계층 분석에서 저장 장치의 선택과 운영 측면이 응답자들이 가장 중요하게 지적한 부분은 실시간 콘텐츠 제작에 있어 발생하는 영 상 데이터의 처리 부분과 맥을 같이 한다고 볼 수 있다. 따라서 기존 Raw File 제작 형태의 $4 \mathrm{~K}-\mathrm{UHD}$ 콘텐츠 제 작 방식이 후반 처리 과정에서 데이터 처리로 인한 시간 적 문제를 실시간 영상처리 워크프로우의 적용으로 $4 \mathrm{~K}-\mathrm{UHDTV}$ 콘텐츠 생산의 프로세스를 개선할 수 있다.

6) Digital Intermediate 의 약자로 고전적인 디지털화 관련된 영 화 마무리 과정, 디지털 후반 작업의 과정 특히 색 보정을 의미하기도 함.

7) HD-SDI 는 High Definition Serial Digital Interface 의 약어 로 디지털 영상 전송 규격 


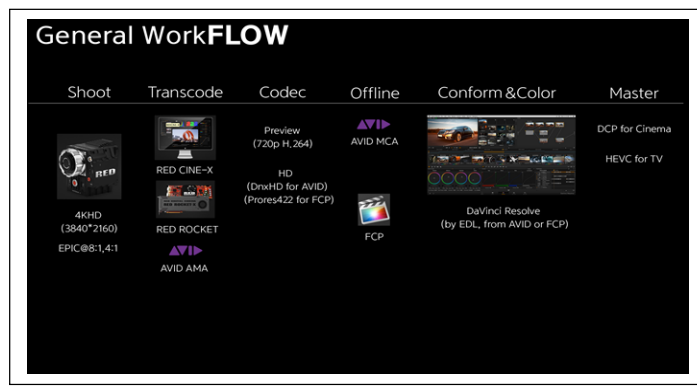

[Fig. 7] 4K production workflow[Source : RED]

\section{5. 결론}

본 연구에서는 $4 \mathrm{~K}-\mathrm{UHDTV}$ 콘텐츠 제작에 관한 워크 플로우 항목을 도출하고 상호 중요도를 평가하기 위한 전문가 상대의 중요도 설문조사를 통하여 얻은 자료를 분석하였다. 평가 툴은 $\mathrm{AHP}$ 를 이용하여 평가 관점과 항 목들을 도출하여 항목들 간의 전략적 우선순위를 산출하 였다. 콘텐츠의 기획 측면, 미디어 파일 관리 측면, 제작 장비의 선택과 운영 측면의 상위 3 가지 1 차 요인과 하위 9 개의 2 차 평가 요소들을 도출하여 이원 비교를 통한 상 대적 중요도를 분석하였다. 1 차 중요도 요인은 제작 장비 의 선택과 운영 측면이 상대적으로 중요하게 분석되었다. 또한 2차 평가 요인으로는 $\mathrm{UHD}$ 제작 $\mathrm{STAFF}$ 간의 역할 과 트레이닝, 미디어 관리, 저장 장치의 선택과 운영이 상 대적으로 중요하게 평가 되었다. $4 \mathrm{~K}-\mathrm{UHDTV}$ 콘텐츠 제 작 워크플로의 문제점과 발전 방향에 대해서는 기존의 RAW File 형태의 제작 과정에서 실시간 콘텐츠 생성이 가능한 워크프로우의 제안도 확인 할 수 있었다.

본 연구에서는 $4 \mathrm{~K}-\mathrm{UHDTV}$ 콘텐츠 제작에 있어 초기 시장 개척과 함께 산재한 여러 가지 문제점들 중에서 $4 \mathrm{~K}-\mathrm{UHDTV}$ 제작 활성화와 고려해야 할 사항은 무엇인 지 살펴보고, $\mathrm{UHD}$ 제작 관련 전문가들이 생각하는 상대 적 중요 요인들을 알아보기 위한 시도를 했다는 점에서 제한적이지만 의의가 있다고 할 수 있다.

\section{ACKNOWLEDGMENTS}

This research was supported by Academic Research grant of Seoul National University of Science \& Technology in 2014.

\section{REFERENCES}

[1] Suk-Hui Jo, Dong-San Jeon, Jin-Su Cho, UHDTV Construction Technology and Standardization. TTA Journal, Vol. 140, 2012.

[2] Guk-jin Kim, Jeon-Gil Choi, Study on the Introduction of terrestrial UHDTV. Korea Communications Commission, 2013.

[3] $4 \mathrm{~K} \& 8 \mathrm{~K}$ UHD technology and industry trends. KCA, PM Issue Report, 2013.

[4] Jong-Hwan Sin, U(H)DTV(Ultra High Definition Television). Internet and security issues, pp.36-39, 2012.

[5] Su-Gang Lee, A Study of the Influence on the Production of Digital Broadcasting Programs by the Introduction of UHDTV. Sejong University master's thesis. 2014.

[6] ITU-R BT 2020, Parameter values for ultra-high definition television systems for production and international programme exchange.

[7] Gu-Man Pak, Youg-Ju Lee, Gwang-Jik Lee, Dong-San Jeon, Jin-Su Choi, and Jin-Wung Kim, UHDTV Video Technology-Consideration Factors in Development and Strategic Policy Evolution. Journal of Information Science, No. 12, 2011.

[8] Sang-Yuong Kim, Ji-Gyun Kim, and Jin-Su Choi, UHDTV broadcasting technology trends and prospects. PM Issue Report, Vo. 1, Issue 6, 2013.

[9] In-kyung Park, Kwang-sung Ha, Mun-churl Kim, Suk-hee Choi, and Jin-Soo Choi, Analysis on Subjective Image Quality Assessments for 4K-UHD Video Viewing Environments. Journal of Broadcast Engineering, Vol.15, Issue 4, 2010.

[10] Sug-Chul Mun, Min-Choel Pak, Sumio Yano, Super high-definition TV's Human Factor. Journal of Broadcast Engineering, Vol. 17, No. 4, 2012.

[11] Se-Yun Jeong, Suk-Hee Jo, Ung-Don Lee, 
Sung-Hun Kim, Jin-Su Choi, and Jin-Woo Hong, UHDTV Technology Status and Prospects. Magazine of the IEEK, Vol. 36, No. 4, pp. 427-435, 2009.

[12] Korea National Institute propagation, UHD TV trends and future prospects related to the latest technology. broadcasting and communication technology issues and outlook, No. 17, 2013.

[13] UHDTV market development patterns and Diffusion conditions. KCA Report, No. 61, pp.66-76, 2013.

[14] Chang-Hee Oh, Hoe-Kyung Jung, A Study for Picture Quality of UHDTV and Production as Realistic Media. HCI Conference, 2014.

[15] Seong-Howan Song, Seog-Hun Kwon, Jin-Bum Pak, and Sun-Gi Hong, Application of the Delphi Technique in Modifying AHP Method. Management Science, Vol. 26, No. 1, p.53-64, 2009.

[16] Sang-Jung Park, Chan Koh, Analysis of Key Factors in Operational Control Transition Resolution using Analytic Hierarchy Process(AHP). The Journal of digital policy \& management, Vol. 9, No. 6, pp.153-163, 2011.

[17] DOI: http://meta.gaja.so/1/2893345

[18] Alaric Hamacher, Sun-Chul Kwun, Seung-Hyun Lee, UHDTV content creation environment changes. Journal of Broadcast Engineering, Vol. 18, No. 2, 2013.

[19] DOI: http://ko.wikipedia.org/wiki/Raw

[20] Jae-Mo Gu, Yung-Hun Gan, Jae-Yung Lim, UHD $4 \mathrm{~K}$ production practices. Korea Creative Content Agency.

[21] SONY, 4K for Live Production PPT.

\section{장 형 준(Chang, Hyung Jun)}

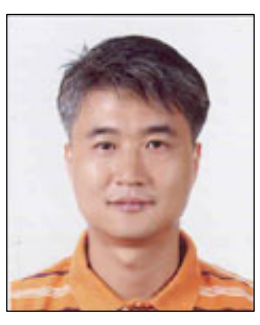

- 2011년 9월 : 한독 미디어 대학원 미 디어 공학 석사

- 2012년 9월 현재 : 서울 과학기술 대학교 IT정책 전문대학원 박사과정 · 1994년 2월 현재 : KBS TV기술 국, $3 \mathrm{D}$ 콘텐츠 제작단 근무

· 관심 분야 : 방송 통신, 실감 방송

·E-Mail : jjangga@kbs.co.kr
김 광 호( $\mathrm{Kim}, \mathrm{Kwang}-\mathrm{Ho})$

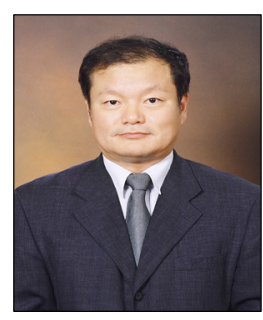

- 1988년 8월 : 독일괴팅겐대 언론학 석사

· 1993년 2월 : 독일괴팅겐대 언론학 박사

- 1995년 3월 현재 : 서울 과학기 술대학교 교수

· 관심 분야 : 방송 통신, 뉴미디어

·E-Mail : kkh@seoultech.ac.kr 